\title{
Seizures and Epilepsies due to Channelopathies and Neurotransmitter Receptor Dysfunction: A Parallel between Genetic and Immune Aspects
}

\author{
Agustina M. Lascano a Christian M. Korff ${ }^{b}$ Fabienne Picard $^{a}$ \\ ${ }^{a}$ EEG and Epilepsy Exploration Unit and bediatric Neurology Unit, Child and Adolescent Department, University \\ Hospitals Geneva, Geneva, Switzerland
}

\section{Key Words}

Channelopathies · Epilepsy · Genetics · Immune system

\begin{abstract}
Despite intensive research activity leading to many important discoveries, the pathophysiological mechanisms underlying seizures and epilepsy remain poorly understood. An important number of specific gene defects have been related to various forms of epilepsies, and autoimmunity and epilepsy have been associated for a long time. Certain central nervous system proteins have been involved in epilepsy or acute neurological diseases with seizures either due to underlying gene defects or immune dysfunction. Here, we focus on 2 of them that have been the object of particular attention and in-depth research over the past years: the N-methyl-D-aspartate receptor and the leucin-rich glioma-inactivated protein 1 (LGI1). We also describe illustrative examples of situations in which genetics and immunology meet in the complex pathways that underlie seizures and epilepsy.

(c) 2016 S. Karger AG, Basel
\end{abstract}

C.K. and F.P. contributed equally to this work.
Despite intensive research activity leading to many important discoveries, the pathophysiological mechanisms at the basis of seizures and epilepsy remain incompletely understood.

The role of genetics has long been studied in the field. An important number of specific gene defects have been related to various forms of epilepsies, to the point that the International League against Epilepsy recently proposed a change in terminology by applying the term 'genetic' instead of 'idiopathic' [Berg et al., 2010]. The enormous technological progress made in very recent years has boosted our understanding in the field. With the emphasis and progressive generalization of the use of next-generation sequencing techniques in the diagnostic approach of patients with epilepsy, weeks without important discoveries in the field are rare. Ion channels and neurotransmitter receptors account for a great number of the proteins whose dysfunction has been associated with seizures, and numerous of their encoding genes have been identified. Among many more, these include sodium, potassium or calcium channels, gamma-aminobutyric acid (GABA), or glutamate receptors.

Similarily, autoimmunity and epilepsy have been associated for a long time. Increasing interest started when a group of patients suffering from Rasmussen's encepha-

\section{KARGER}

E-Mail karger@karger.com

www.karger.com/msy (c) 2016 S. Karger AG, Basel

1661-8769/16/0074-0197\$39.50/0
Dr. Christian M. Korff

Pediatric Neurology Unit, Child and Adolescent Department

University Hospitals Geneva, 6 Rue Willy Donzé

$\mathrm{CH}-1211$ Geneva 14 (Switzerland)

E-Mail christian.korff@hcuge.ch 
litis were found to have circulating anti-GluR3 IgG antibodies in their serum [Rogers et al., 1994], even though later studies showed that this relationship between antibodies against GluR3 peptides and Rasmussen's encephalitis was unclear [Mantegazza et al., 2002]. Up to now, identified antibodies against ion channels mostly target synaptic voltage-dependent channels and ligand-gated receptor channels. Antibodies can be detected in the serum and/or cerebrospinal fluid (CSF) of symptomatic patients. They include voltage-gated potassium channel (VGKC) complex [Lai et al., 2010; Lee et al., 2014], Nmethyl-D-aspartate (NMDA) glutamate receptor [Dalmau et al., 2011], gamma-aminobutyric acid $A\left(G_{A B A}\right)$ and $\mathrm{B}\left(\mathrm{GABA}_{\mathrm{B}}\right)$ receptors [Kruer et al., 2014; Petit-Pedrol et al., 2014], glycine receptor [Carvajal-González et al., 2014], dipeptidyl-peptidase-like protein-6 (a subunit of the Kv4.2 potassium channel) [Boronat et al., 2013], metabotropic glutamate receptor 5 [Lancaster et al., 2011], and alpha-amino-3-hydroxy-5-methyl-4-isoxazolepropionic acid receptors (AMPAR) [Joubert et al., 2015]. During the past years, knowledge on autoantibodies and associated neuropsychiatric manifestations including epilepsy has skyrocketed.

Interestingly, certain of the above-mentioned central nervous system (CNS) proteins have been involved in epilepsy or acute neurological diseases with seizures either due to underlying gene defects or immune dysfunction. Here, we focus on 2 of them that have been the object of particular attention and in-depth research over the past years: the NMDA receptor and the leucin-rich glioma-inactivated protein 1 (LGI1) related to the VGKC complex. We also describe illustrative examples of situations in which genetics and immunology meet in the complex pathways that underlie seizures and epilepsy.

\section{Part 1: NMDA Glutamate Receptors}

NMDA receptors are ligand-gated ion channels composed of 2 glycine-binding NR 1 and 2 glutamate-binding NR2 subunits. These receptors are widely distributed in all regions of the CNS and carry important functions in brain development and cognition [Endele et al., 2010; Aida et al., 2012; Turner et al., 2015a, b]. Well-delineated, but nevertheless very different clinical pictures have been linked with mutations in the genes that encode subunits of the receptor and with circulating autoantibodies targeting one of these subunits. The following paragraphs briefly describe these entities.
Epilepsy and Seizures Linked to Mutations in NMDA Receptor Genes

GRIN2A

Abnormalities in GRIN2A, the gene that encodes NR2A, the alpha-2 subunit of the NMDA receptor, have been recently reported in patients with idiopathic focal epilepsies with rolandic spikes, including benign epilepsy with centrotemporal spikes (BECTS), Landau-Kleffner syndrome, and epileptic encephalopathy with continuous spike-waves during slow sleep (CSWS) [Carvill et al., 2013; Lemke et al., 2013; Lesca et al., 2013; Conroy et al., 2014; Turner et al., 2015a, b].

In one of the 3 seminal papers published simultaneously in 2013 on that topic, new heterozygous mutations were discovered in 27 (7.5\%) of 359 affected individuals from 2 independent cohorts with idiopathic focal epilepsies. Twelve (4.9\%) of 245 patients with BECTS and 9 (17.6\%) of 51 patients with CSWS had mutations, indicating a possible correlation between phenotype severity and an increased risk of carrying a mutation [Lemke et al., 2013]. In that article, functional analysis of a missense mutation found in one of the patients suggested increased activation of the NR1-NR2 heteromer, contrasting with data resulting from previous studies on other types of mutations affecting the same gene [Lemke et al., 2013].

In a second article, GRIN2A deletions and point mutations were detected in $20 \%$ of familial and sporadic cases of Landau-Kleffner syndrome, CSWS, and atypical rolandic epilepsy often associated with speech disorders [Lesca et al., 2013].

In the third article, in a total of 519 patients with epileptic encephalopathies, 4 (9\%) of 44 patients with epilepsy-aphasia syndromes had pathogenic GRIN2A mutations. These 4 patients all belonged to families in which several members were diagnosed with conditions in the same epilepsy-aphasia syndromes spectrum. In that cohort, GRIN2A mutations were neither identified in any of the other encephalopathies, nor in patients with BECTS [Carvill et al., 2013].

This last finding was later confirmed in another study on a large group of patients with either generalized epilepsy or so-called 'temporal lobe epilepsy', in which none of several hundreds of patients with these conditions had mutations in GRIN2A [Lal et al., 2015].

Additional variable phenotypes have been associated with GRIN2A in patients with seizures [Endele et al., 2010]. Further studies are necessary to better understand the protein function and genotype-phenotype associations. 


\section{GRIN2B}

Mutations in GRIN2B, the gene encoding NR2B, the beta- 2 subunit of the NMDA receptor, have been reported in patients with intellectual disability [Endele et al., 2010] and various neuropsychiatric conditions, such as disruptive behavior [Lee et al., 2016], autism [Pan et al., 2015], and Tourette syndrome [Che et al., 2015]. However, epilepsy does not seem to be predominant in most conditions related to GRIN2B product dysfunction [Endele et al., 2010]. In a large cohort of 264 children with West syndrome or Lennox-Gastaut syndrome screened by exome sequencing, only one was identified as carrying a de novo mutation in GRIN2B [Epi4K Consortium et al., 2013]. To our knowledge, only rare additional patients with West syndrome or focal seizures (all in the context of developmental delay/intellectual disability) and GRIN2B mutations have been reported since [Lemke et al., 2014].

\section{NMDA Receptors as Antigenic Targets of Circulating} Autoantibodies

Circulating antibodies against glutamatergic NMDAreceptor (NMDAR) subunits have been reported in association with various forms of encephalitis and seizures. Animal studies showed that antibodies mainly react against the extracellular N-terminal domain of the NR1 subunit of the NMDAR [Dalmau et al., 2008]. The presence of anti-NMDAR antibodies has been shown to provoke an increase in the NMDAR internalization rate in hippocampal neurons, subsequent decrease in NMDARmediated currents, and a decrease in inhibitory synapse density onto excitatory hippocampal neurons [Hughes et al., 2010; Moscato et al., 2014]. Brain biopsies performed in rare patients show mild perivascular lymphocytic cuffing, microglial activation, or normal findings [Dalmau et al., 2008].

In the initial cases reported, these antibodies were considered as nonspecific markers of an ongoing autoimmune process. Later, however, these antibodies were clearly identified as being directly responsible for a homogeneous association of neuropsychiatric symptoms observed in many patients [Dalmau et al., 2007, 2008]. The patients present with a characteristic sequence of behavioral or cognitive changes of subacute appearance (days to weeks) followed by transient seizures. In the series published in $2008,76 \%$ of patients had seizures in the first 3 weeks of the disease. These were of various types, including focal motor or dyscognitive, generalized tonicclonic, and refractory status epilepticus or epilepsia partialis continua [Dalmau et al., 2008]. Focal (mostly tonic) seizures with a suggestive ictal-onset pattern (rhythmic and sharp 6-12 $\mathrm{Hz}$ activity with a subsequent spread to one or both hemispheres) have also been reported in children [Sands et al., 2015]. A severe movement disorder, including orofacial dyskinesias, dystonia, and choreoathetosis, is subsequently observed. Central hypoventilation, sleep disturbances (in form of hyper- or hyposomnia), and autonomic dysfunction may be noted as well. This quite homogeneous clinical presentation was individualized as 'anti-NMDAR encephalitis' in the groundbreaking article of 2008 [Dalmau et al., 2008]. It has been shown since that anti-NMDAR antibodies are one of the most frequent causes of encephalitis in children and young adults, all infectious and inflammatory etiologies included, as demonstrated recently in a large cohort study [Gable et al., 2012].

Since 2008, multiple patients have been reported, including children whose presentation closely resembles that of adults, although dysautonomia and respiratory troubles may be more frequent or severe in the latter [Florance et al., 2009]. One report of a transplacental transfer of NMDAR antibodies in a child who was later diagnosed with abnormal neonatal movements, developmental delay, seizures, and cortical dysplasia has been published recently [Jagota et al., 2014]. The question whether all or part of this child's clinical symptoms and findings result from the transfer of maternal antibodies remains unanswered.

NMDAR antibodies are frequently found in the CSF of patients. Additional findings in that compartment may include an elevated cellular (mostly lymphocytic) and protein count as well as oligoclonal distribution. Three distinct clinical-radiological syndromes involving the white matter were recently identified in children with anti-NMDAR encephalitis [Hacohen et al., 2014]. Some of these patients had associated antibodies involved in demyelination, such as those targeting myelin oligodendrocyte glycoprotein. In many patients, structural MRI remains normal. FDG-PET scan studies have shown variable sites of involvement in a few patients, such as hypermetabolism in the basal ganglia and cortical hypometabolism in a patient with prominent abnormal movements, and hypermetabolism in the left prefrontal and anterior cingulate cortex in another patient with psychiatric features and seizures [Maeder-Ingvar et al., 2011; Chanson et al., 2012]. Functional imaging studies recently showed reduced functional connectivity of both hippocampi and extensive white matter changes on diffusion tensor imaging sequences, most prominent in the cingulate cortex [Finke et al., 2013]. The EEG most often shows 
Table 1. Comparison between epilepsy related to NMDAR autoantibodies and to GRIN2A mutations

\begin{tabular}{|c|c|c|}
\hline & Autoimmune & Genetic \\
\hline Etiology & $\begin{array}{l}\text { unknown, alleged predisposition to } \\
\text { autoimmune diseases }\end{array}$ & mutation in GRIN2A \\
\hline Age of onset & $\begin{array}{l}\text { mostly young adults, rarely children, } \\
\text { female predominance }\end{array}$ & childhood \\
\hline Symptom development & $\begin{array}{l}\text { subacute onset, long course (months) and } \\
\text { possible recurrence, seizures often transient } \\
\text { at disease onset }\end{array}$ & $\begin{array}{l}\text { subacute/acute onset of clinical } \\
\text { features including acquired auditory } \\
\text { aphasia related to sleep EEG } \\
\text { abnormalities, rare seizures in most } \\
\text { cases }\end{array}$ \\
\hline Ictal presentation & $\begin{array}{l}\text { focal motor or dyscognitive seizures, } \\
\text { generalized seizures, status epilepticus, } \\
\text { epilepsia partialis continua }\end{array}$ & focal motor seizures in most cases \\
\hline Interictal presentation & behavioral troubles, cognitive difficulties & $\begin{array}{l}\text { asymptomatic or acquired aphasia, } \\
\text { loss of speech, behavioral troubles }\end{array}$ \\
\hline Other findings & $\begin{array}{l}\text { movement disorder, sleep difficulties, } \\
\text { autonomic dysfunction }\end{array}$ & none reported \\
\hline EEG & $\begin{array}{l}\text { focal or diffuse continuous theta and delta } \\
\text { slowing, superimposed low-voltage fast } \\
\text { activity (extreme delta brush pattern) }\end{array}$ & $\begin{array}{l}\text { biphasic stereotyped centrotemporal } \\
\text { spike-waves, may become continuous } \\
\text { during sleep, especially if cognitive } \\
\text { decline is noted }\end{array}$ \\
\hline Brain MRI & $\begin{array}{l}\text { frequently normal, may show white matter } \\
\text { abnormalities }\end{array}$ & normal \\
\hline Treatment & $\begin{array}{l}\text { refractory to AED, recover with } \\
\text { immunotherapy and extended intensive } \\
\text { care support }\end{array}$ & $\begin{array}{l}\text { seizures AED responsive, EEG } \\
\text { abnormalities often refractory }\end{array}$ \\
\hline Outcome & $\begin{array}{l}\text { appropriate treatment started early, } \\
\text { complete recovery is the rule; cognitive or } \\
\text { motor sequeleae may be observed, rare } \\
\text { deaths reported }\end{array}$ & cognitive sequeleae often observed \\
\hline
\end{tabular}

a slow background activity with monotonous features that suggest a predominant involvement of subcortical structures. All of the EEGs performed on the patients reported in 2008 were abnormal: of 92 patients for whom information was available, 71 had slowing and 21 had epileptic activity [Dalmau et al., 2008]. Low-voltage fast rhythms may be superimposed on slow waves, creating the socalled and easily recognizable 'extreme delta-brush' pattern [Schmitt et al., 2012; Armangue et al., 2013].

The disorder may be associated with tumors, frequently located in the ovaries in young women. This association seems much less common in children [Florance et al., 2009]. Symptoms are typically refractory to all neuroand psychoactive drugs but most often respond well to immunotherapy and tumor removal [Titulaer et al.,
2013]. Immune treatment recommendations include the aggressive use of steroids, plasma exchanges, and immunoglobulins as first-line approaches, rapidly followed by monoclonal antibodies (rituximab) and cyclophosphamide in case of refractoriness [Dalmau et al., 2008; Florance et al., 2009; Titulaer et al., 2013]. Complete disappearance of symptoms can be expected, but recovery may take up to 18 months; a minority of patients may die during their illness [Titulaer et al., 2013].

The main clinical differences between epilepsy related to GRIN2A mutations and anti-NMDAR encephalitis are described in table 1 . Since both entities share different pathophysiological mechanisms, it is not surprising that clinical presentation differs between them. Another main difference lies in the treatment response. Autoimmune- 
mediated epilepsy is a potentially reversible episodic phenomenon by means of immunomodulatory treatment, while genetically determined disorders may persist due to an absence of causal therapy.

\section{Part 2: Voltage-Gated Potassium Channel Complex/ LGI1}

LGI1 is a protein linked to the VGKC complex and whose mutations or autoimmune pathology may cause epilepsy. The discovery of LGI1 has raised great interest in epilepsy research since it was the first epilepsy-related gene appearing to code for a protein and not for an ion channel. Only later studies identified its close relationship with the VGKC complex [Irani et al., 2010]. LGI1 was then shown to be the major target of human autoantibodies which immunoprecipitate VGKC complexes from mammalian brain tissue, while contactin-associated proteinlike 2 (CASPR2) is the second antigenic neuronal target.

LGI1 belongs to large synaptic protein complexes linked to VGKC and is associated with the disintegrin and metalloprotease domain-containing proteins (ADAM)22 and ADAM23. By binding to ADAM22 and ADAM23, LGI1 also acts on AMPAR, which are glutamate receptors and cation channels at the postsynaptic membrane. LGI 1 is also complexed with Kv1.1-containing presynaptic VGKC and prevents its fast inactivation, possibly via interaction between ADAM23 and the intracellular $\operatorname{Kv} \beta 1$ subunit [Fukata et al., 2010; Crisp et al., 2016]. In total, LGI1 participates in a trans-synaptic protein complex that includes presynaptic potassium channels and postsynaptic AMPAR.

Besides LGI1, mutations in other potassium channels have been involved in other epileptic syndromes: KCNQ2 and $K C N Q 3$ are genes whose mutations cause familial benign neonatal convulsions [Singh et al., 2003] as well as early-onset epileptic encephalopathies [Weckhuysen et al., 2012]. To our knowledge, there are no known mutations inducing epilepsy in the KCNA1 gene encoding the Kv1.1 channel (on which LGI1 acts), except in mice models [Robbins and Tempel, 2012], but KCNA1 mutations cause another paroxysmal neurological disorder - episodic ataxia type 1 [Graves et al., 2014].

\section{Autosomal Dominant Partial Epilepsy with Auditory Features/LGI1 mutations}

The LGI1 gene, also called epitempin, is located in chromosome 10q22 and encodes a protein (LGI1) which was first found to have a tumor suppressor function. Mis-

Seizures and Channelopathies, Genetic and Immune Aspects sense or truncating mutations as well as microdeletions were shown to be involved in a rare form of lateral temporal lobe epilepsy with auditory auras, known as autosomal dominant partial epilepsy with auditory features (ADPEAF), autosomal dominant epilepsy with auditory features [Gu et al., 2002; Klein et al., 2013], or autosomal dominant lateral temporal lobe epilepsy [Pisano et al., 2005]. Diagnosis of ADPEAF is fulfilled whenever 2 or more family members experience auditory auras or sensory aphasic seizures [Ottman, 2007].

The prevalence of this affection is currently unknown, with dozens of families reported, particularly in Italy [Michelucci et al., 2013]. The age of onset is variable ranging from 8 to 50 years [Michelucci et al., 2003] but usually emerging in adolescence and early childhood [Ho et al., 2012]. Clinical presentation is characterized by simple auditory auras such as ringing, humming and mainly buzzing with a progressive increased intensity $(>50 \%)$, sometimes followed by a secondary generalization (66\%) [Michelucci et al., 2013]. More complex auditory symptoms have been described but remain an infrequent clinical complaint. Seizures with prominent auditory auras are sometimes triggered by external noises [Michelucci et al., 2003; Pisano et al., 2005]. Language ictal disturbances (i.e., aphasia) have also been reported as a frequent clinical feature [Michelucci et al., 2003]. Autonomic manifestations, classically observed in mesial temporal lobe epilepsy, were not described in 8 families suffering from ADPEAF of European ancestry [Ottman et al., 2004]. Less frequently, other types of auras such as visual, motor, dyscognitive, and even vertigo have been reported [Dazzo et al., 2015; Klein et al., 2016].

Interictal EEG shows rhythmic epileptiform temporal abnormalities such as focal slowing or sharp waves in up to $2 / 3$ of individuals with a slightly left predominance [Brodtkorb et al., 2002]. EEG was reported as normal or showing nonspecific changes in about one third of the patients [Michelucci et al., 2013]. Structural MRI is sought to be unremarkable; however, subtle focal abnormalities such as temporal lobe enlargement or atrophy have been rarely described [Kobayashi et al., 2003; Tessa et al., 2007].

Approximately 40 LGI1 mutations accounting for $\sim 50 \%$ of the affected families have been reported in the literature so far [Michelucci et al., 2003; Ottman et al., 2004]. These mutations preferentially involve the N-terminal leucine-rich repeat (LRR) responsible for proteinprotein interface. An average penetrance of $66 \%$ has been reported, but selection bias is suspected since they are based on families selected for the study containing a large number of affected individuals [Rosanoff and Ottman, 
2008]. Clinical differences could partly be explained by the presence of diverse types of mutations in the LGI1 gene. A recent study by Ho et al. [2012] tried to establish a genotype-phenotype correlation by showing that families with few auditory auras had truncation mutations in the epitempin domain (exons 7,8 ) instead of the LRR region (exons 1-6). This would mean that even though mutations in the epitempin and the LRR domain are clearly pathogenic, LRR is more frequently associated with 'typical forms' of ADPEAF.

As opposed to ADPEAF, sporadic cases seldom present with LGI1 de novo gene mutations (around 2\%) [Bisulli et al., 2004; Nobile et al., 2009; Kesim et al., 2015]. This finding was confirmed by a study comparing a group of 16 patients with a sporadic form of idiopathic partial epilepsy with auditory features versus European families with a known LGI1 mutation [Flex et al., 2005]. Clinical presentation, disease evolution, and response to antiepileptic drugs (AED) are sought to be the same in both groups [Bisulli et al., 2004].

Notwithstanding the genetic evidence underlying ADPEAF, the pathogenic mechanisms leading from an LGI1 mutation to focal epilepsy remain elusive. It has been hypothesized that LGI1 deficiency triggers epilepsy as a result of a faulty interaction with the proteins ADAM22 and 23, which affects AMPAR-mediated synaptic transmission [Fukata et al., 2010]. More recently, it was shown that LGI1 depletion in glutamatergic pyramidal neurons applied in conditional knockout mice generates seizures per se, at any moment of the neural development, independently if it occurs in the prenatal (i.e., mimicking familial ADPEAF) or the postnatal period [Boillot et al., 2014]. The defect was only patent when it affected glutamatergic neurons and not GABAergic neurons. In addition, further evidence suggests that mutant LGI1 inhibits dendritic and synaptic pruning of glutamatergic neurons during the postnatal period and thus markedly increases excitatory synaptic transmission in transgenic mice expressing a truncated mutant form found in ADPEAF [Zhou et al., 2009]. Alternatively, another hypothesis involved the fact that LGI1 could prevent the fast inactivation of presynaptic VGKC Kv1.1 [Schulte et al., 2006], possibly by an interaction between ADAM23 and the intracellular Kv $\beta 1$ subunit [Crisp et al., 2016]. Moreover, recent evidence suggests that LGI1 deficiency results in a presynaptic dysfunction leading to an increased glutamatergic synaptic transmission [Yu et al., 2010; Boillot et al., 2016]. In summary, all LGI1 mutations induce a loss of function of the protein (haploinsufficiency), whether by a loss of expression ( $1 / 3$ of the mu- tations), or an absence of secretion or absence of interaction with its main receptor, ADAM22.

New light has been shed regarding the genetic heterogeneity of ADPEAF; a recent Italian-American study has identified 7 heterozygote missense mutations in the RELN gene in 7 families with ADPEAF showing no LGI1 mutations [Dazzo et al., 2015]. RELN encodes REELIN, a glycoprotein regulating neuronal migration [Hong et al., 2000], which does not seem to interfere with channels.

\section{Limbic Encephalitis Associated with Anti-LGI1 Antibodies}

VGKC-related autoimmune disorder includes distinct clinical syndromes ranging from pure peripheral to exclusive CNS involvement. At one extreme, acquired neuromyotonia, or Isaacs' syndrome, presents with peripheral motor nerve hyperexcitability [Vincent, 2010]. At the other end of the scale, limbic encephalitis (LE) is defined by its exclusive CNS involvement and characterized by psychosis, cognitive disturbances, sleep disorder, myoclonus, and seizures of acute or subacute onset [Pollak et al., 2014; Crisp et al., 2016]. Unlike some forms of neuromyotonia, only $\sim 10 \%$ of VGKC-related LEs are associated with tumors, whether from lung, thyroid, kidney, ovary, or thymus [Irani et al., 2010; Lai et al., 2010] and are, thus, potentially reversible in $\sim 90 \%$ of patients receiving immunosuppression [Tan et al., 2008]. Supportive criteria comprise personal or familial history of other autoimmune diseases, pleocytosis in CSF, and nonspecific white matter changes depicted on MRI [Ekizoglu et al., 2014], whereas exclusion criteria include other causes such as infectious, metabolic, or toxic. In addition, oligoclonal distribution, considered as a confirmative element of a CNS autoimmune process, can be detected in $\sim 50$ $60 \%$ of all patients at one stage of the disease.

Phenotypic heterogeneity of VGKC-related disorders can be explained by the fact that autoantibodies are directed towards other neural proteins that coprecipitate with Kv1.1 subunits, but not to the complex itself [Lai et al., 2010; Vincent and Irani, 2010]. A recent scientific breakthrough has shown that autoimmune LE, previously attributed to VGKC-complex antibodies, is mostly due to autoantibodies targeting LGI1 [Lai et al., 2010]. LGI1 and CASPR2 have been identified as the major targets of potassium channel antibodies [Irani et al., 2010; Klein et al., 2013].

LE associated with anti-LGI1 antibodies mainly affects patients in their seventh decade (mean age: 60 years; range: $30-80$ years) with a slight male predominance [Lai et al., 2010]. Subacute and progressive altered conscious- 
ness, prominent amnesic features (100\%), drop attacks $(62 \%)$, and faciobrachial dystonic seizures (FBDS) (82$90 \%$ ) associated with temporal lobe EEG discharges characterize LE associated with LGI1 antibodies [Andrade et al., 2011; Irani et al., 2011]. Besides the constantly observed memory loss and the frequent epileptic focal seizures, myoclonia (present in $40 \%$ of all cases) and hyponatremia (60\% of all cases, with a mean level of 128 $\mathrm{mmol} / \mathrm{l}$ ) are frequently encountered [Lai et al., 2010].

Stereotypic, brief ( $<3$ seconds) and unilateral facial grimacing $(76 \%)$ and dystonic posturing of the ipsilateral upper limb, appearing several times a day, constitute the hallmark of FBDS [Lai et al., 2010]. This clinical manifestation can appear from one to several months before the onset of cognitive disturbances [Irani et al., 2011]. FBDS seems to be related with LGI1 antibodies, since no FBDS was reported in 5 Korean patients with CASPR2 antibodies [Sunwoo et al., 2015]. Even though ictal and peri-ictal dysautonomic features such as tachychardia, blood pressure abnormalities, or hypersalivation are primarily observed in anti-NMDAR encephalitis (see above, Part 1) or Caspr2 encephalitis [Baysal-Kirac et al., 2016], pilomotor seizures [Rocamora et al., 2014] and bradycardia [Naasan et al., 2014] were respectively described in $3 / 5$ and in $3 / 14$ patients in association with LGI1 antibodies.

Interictal EEG shows a continuous theta and delta diffuse slowing in about $75 \%$ of the patients with autoimmune LE [Baysal-Kirac et al., 2015]. Ictal abnormalities showed a frontotemporal, frontal or temporal focus [Irani et al., 2011].

Brain MRI depicted an increased T2/FLAIR signal involving one or both mesial temporal lobe(s) in 43/57 patients with LGI1-mediated LE in the acute/subacute phase [Lai et al., 2010]. In addition, a voxel-based morphometry study showed a gray matter volume increase in both amygdalas in LGI1-mediated LE as opposed to anti-glutamic acid decarboxylase-associated LE [Wagner et al., 2015]. A 3-year follow-up study showed global brain atrophy with hippocampal sclerosis in one patient who did not receive immunosuppressive therapy [Szots et al., 2014].

CSF analysis is abnormal in about $40 \%$ of the patients with either elevated protein or lymphocytic pleocytosis [Lai et al., 2010].

The epileptic seizures respond more favorably to immunosuppression than to AED, often showing cutaneous side effects ranging from a local rash to Stevens-Johnson syndrome in AED-treated patients [Irani et al., 2011]; on the other hand, an early immunotherapy may prevent the appearance of cognitive impairment [Irani et al., 2013].
Falls in serum of VGKC antibodies were correlated with an improvement in neuropsychological tests in $6 / 10 \mathrm{pa}$ tients [Vincent et al., 2004]. Moreover, recovery time was highly correlated with the speed of treatment onset. The faster the treatment was introduced, the more rapid the clinical recovery was achieved. Steroids and intravenous immunoglobulins have been the more frequently administered treatments, whereas plasma exchanges are more rarely used. The outcome is a full recovery of all symptoms in a quarter of the patients, mild disability in $54 \%$, moderate disability in 16\%, and death in $6 \%$ in the study of Lai [Lai et al., 2010].

Understanding the pathogenic mechanisms of this disease is of utmost importance in treatment decisionmaking. Most likely, different autoimmune synaptic encephalopathies carry diverse antibody-mediated mechanisms. One hypothesis elaborated by Ohkawa et al. [2013] suggests that binding of antibodies to LGI1 disrupts the ligand-receptor interaction of LGI1 with ADAM 22. The latter interacts with postsynaptic density protein 95 (PSD-95), also known as DLG4, thus leading to a reduction in the amount of AMPARs in the synapses. A different mechanism but a similar result (i.e., decrease in AMPARs) is observed in AMPAR-related LE, explaining why similar clinical presentations are observed in both cases, despite the strong association with an underlying tumor in the latter [Höftberger et al., 2015]. Interestingly, AMPARs mediate fast excitatory as well as long-term potentiation of synaptic transmission in the CNS, which are mechanisms implicated in memory consolidation [Granger et al., 2013], a feature that is disturbed in both AMPAR and LGI1-mediated LE. Increased intrinsic hyperexcitability could be responsible for ictal manifestations [Peng et al., 2015]. Despite the fact that LGI1 antibodies are mainly an IgG4 subclass of IgG, strong evidence points out complement-mediated mechanisms as a plausible cause of hippocampal injury [Bien and Bauer, 2014]. No matter which of these hypotheses is considered valid, these changes at a molecular level can be translated as a synaptic function reduction of VGKC containing LGI1 (irreversible effect of the antibodies on the VGKCrelated antigens) and, thus, increased excitability, as shown by a work on rat hippocampal slices after administration of VGKC antibodies from a patient [Lalic et al., 2011].

The small sample size and uncontrolled nature of most studies constitute a major limitation in assessing treatment efficacy. To our knowledge, no controlled, randomized trial has been performed showing superiority of a particular first-line therapy: plasma exchange, 
Table 2. Comparison between epilepsy related to LGI1 autoantibodies and to LGI1 mutations

\begin{tabular}{|c|c|c|}
\hline & Autoimmune & Genetic \\
\hline Etiology & $\begin{array}{l}\text { unknown, alleged predisposition to } \\
\text { autoimmune diseases }\end{array}$ & $\begin{array}{l}\text { mutation in LGI1 (chromosome } \\
10 \mathrm{q} 22 \text { ) }\end{array}$ \\
\hline Age of onset & $\begin{array}{l}\text { adult: } 30-80 \text { years (median } 60 \text { years), } \\
\text { male predominance }\end{array}$ & childhood/adolescence \\
\hline Symptom development & brutal onset, monophasic course & $\begin{array}{l}\text { lifetime condition, no disease } \\
\text { progression }\end{array}$ \\
\hline Ictal presentation & $\begin{array}{l}\text { FBDS; status epilepticus; mesial } \\
\text { temporal seizures without auditory } \\
\text { features; autonomic dysfunction such } \\
\text { as bradycardia, hypersalivation, and } \\
\text { piloerection; drop attacks }\end{array}$ & $\begin{array}{l}\text { focal seizure with auditory auras } \\
\text { (simple or complex) and secondary } \\
\text { generalization; other sensory, motor, } \\
\text { and dyscognitive auras rarely reported; } \\
\text { no reported autonomic manifestations }\end{array}$ \\
\hline Interictal presentation & psychosis; memory loss & asymptomatic \\
\hline Other findings & hyponatremia & none reported \\
\hline EEG & $\begin{array}{l}\text { continuous theta and delta slowing, } \\
\text { temporal or frontotemporal lobe } \\
\text { discharges }\end{array}$ & $\begin{array}{l}\text { interictal epileptiform temporal } \\
\text { abnormalities such as focal slowing or } \\
\text { sharp waves with a slightly left } \\
\text { predominance, } 1 / 3 \text { showed normal } \\
\text { EEG or nonspecific abnormalities }\end{array}$ \\
\hline Brain MRI & $\begin{array}{l}\text { increased T2/FLAIR signal involving } \\
\text { one or both mesial temporal lobe during } \\
\text { acute phase, global brain atrophy and } \\
\text { hippocampal sclerosis }>3 \text { years after } \\
\text { disease onset }\end{array}$ & $\begin{array}{l}\text { normal or minor abnormalities such as } \\
\text { temporal lobe malformation, temporal } \\
\text { arachnoidal cysts, mild ventricular } \\
\text { asymmetry, white matter gliotic } \\
\text { changes, or mild hippocampal atrophy }\end{array}$ \\
\hline Treatment & $\begin{array}{l}\text { refractory to AED, recover with } \\
\text { immunotherapy and extended intensive } \\
\text { care support }\end{array}$ & AED responsive \\
\hline Outcome & $\begin{array}{l}\text { dependent on treatment onset, possible } \\
\text { cognitive deficits }\end{array}$ & benign \\
\hline
\end{tabular}

intravenous immunoglobulin, or pulse intravenous methylprednisolone. Second-line therapy such as rituximab, cyclophosphamide or both has not been applied in LE associated with LGI1 antibodies so far; however, treatment association resulted in favorable clinical outcome in patients with VGKC-complex LE [Wong et al., 2010]. In a recent review by Bien and Bauer [2014], the potential use of eculizumab as an attractive therapeutic option has been tackled, given its encouraging results in other complement-mediated CNS disorders such as neuromyelitis optica spectrum disorder. In any case, early recognition of LE and intractable seizures or status epilepticus as possible features of autoimmune synaptic encephalopathy would allow for prompt introduction of immunotherapy in order to treat the epileptic seizures and prevent future cognitive disturbances, such as epi- sodic memory and verbal fluency disturbances, and long-term brain MRI changes [Irani et al., 2011; Szots et al., 2014].

Thus, it appears that either genetic or acquired loss of the LGI1-ADAM22 interaction will reduce the function of the AMPAR and favor seizures and epilepsy [Ohkawa et al., 2013]. The main clinical differences between epilepsy related to LGI1 mutations and encephalitis associated with anti-LGI1 antibodies are described in table 2.

\section{Part 3: The Relation between Immunity and Genetics}

Autoimmune disorders are defined by the expression of autoantibodies causing antibody- or cell-mediated damage, possibly in genetically susceptible individuals 
and in the presence of predisposing environmental factors [Picascia et al., 2015]. A strong association between seizures and autoimmune diseases is indubitable. In a recent population-level study, Ong et al. [2014] showed that the risk of having epilepsy was more important in patients with one of the 12 common systemic autoimmune diseases studied, as compared to control subjects without such conditions. The overall relative risk of epilepsy was 3.8 times higher in adults, and 5.2 times higher in children with any of these conditions. Patients with autoimmune diseases collectively accounted for $17.5 \%$ of all patients with epilepsy of the entire population [Ong et al., 2014]. Inherited gene defects and somatic mutations allowing a higher affinity for infectious microorganisms could 'accidentally' trigger autoimmune disease, resulting in a ruthless growth of self-reactive $\mathrm{B}$ and $\mathrm{T}$ lymphocyte 'forbidden clones' leading to intrathecal or intraparenchymal antibody production [Adams and Knight, 2003].

The concept of autoimmune epilepsy has recently arisen. Specific signaling cascades of the innate immune system, activated by various 'external' stimuli (such as stroke, trauma, etc.), have been hypothesized as playing a major role in immune predisposition leading to epilepsy. These include the production of interleukin-1 beta (IL-1 $1 \beta$ ) by activated astrocytes and microglial cells, leading to increased neuronal excitability and increased secretion of high mobility group box 1 from necrotic cells, interacting with Toll-like receptor 4 (TLR-4, a pathogen recognition receptor and mediator of inflammation response) to activate neuroglial gene transcription of factors involved in inflammation, astrocyte dysfunction, neurogenesis, and sprouting [Matin et al., 2015]. Additional inflammation factors, such as IL-8 and ATF-3, have also been related to epilepsy, but gene expression studies on human tissue from pharmacoresistant patients with temporal lobe epilepsy seem to indicate that the concentration of these factors is inversely correlated with seizure frequency [Pernhorst et al., 2013].

In any case, these mechanisms remain poorly known [Bien and Bauer, 2014]. It is still unclear why certain patients with seizures show signs of CNS or systemic immune system involvement and whether these mechanisms are at the basis of or appear in reaction to seizures is unknown. It is nevertheless tempting to hypothesize the existence of a possible direct link between genetic predisposition to immune system dysfunction in certain forms of seizures and epilepsies. The following illustrative examples may bring new insights to our understanding of the question.

Seizures and Channelopathies, Genetic and Immune Aspects
Febrile Seizures

Febrile seizures (FS) are the most common form of seizures observed in the general population. They concern $2-5 \%$ of affected children, mostly aged between 6 months and 5 years [Stafstrom, 2002]. A recent multicentric prospective study evaluated long-term consequences of febrile status epilepticus on 200 children and showed MRI (hippocampal and temporal lobe) [Shinnar et al., 2012] and EEG abnormalities (1/3 presented focal temporal slowing) [Nordli et al., 2012] within the first $72 \mathrm{~h}$, while CSF analysis was unremarkable [Frank et al., 2012].

Family history of febrile seizures is frequently positive, suggesting underlying genetic predisposition for an abnormal response to fever. Among others, mutations in genes coding for sodium channels or GABA receptors were identified in certain families with FS [Greenberg and Holmes, 2002]. Additional data, in particular from twin studies, indicate that inheritance is probably heterogeneous and polygenic, and that environmental factors are likely to be important in the pathogenesis of FS. Inflammatory response components, such as those involved in the interleukin 1 (IL-1) system, have been suspected to play a role in FS [Gatti et al., 2002]. Recent reports indicate that certain SNPs in genes that encode other inflammation-related molecules, such as IL-6 [Shahrokhi et al., 2014], IL-6 receptor, prostaglandin E receptor 3, purinergic receptor P2X7, or TLR-4, may be involved in the pathogenesis of FS [Emsley et al., 2014].

\section{Post-Traumatic Epilepsy}

The expression and concentration profile of IL- $1 \beta$, a proinflammatory cytokine, was recently studied in patients with post-traumatic epilepsy [Diamond et al., $2014]$. IL- $1 \beta$ is produced in the CNS by activated microglia and astrocytes, and in the blood mostly by macrophages; it was previously demonstrated to be increasingly expressed and chronically released after traumatic brain injury, and hence, to contribute to the appearance of subsequent post-traumatic epilepsy in certain patients [Ferrari et al., 1996; Lu et al., 2005; Diamond et al., 2014]. A specific SNP in $I L-1 B$, the gene that encodes IL- $1 \beta$, had itself been involved in certain forms of nontraumatic temporal lobe epilepsy in other studies [Kauffman et al., 2008]. Based on these data, the aim of the study by Diamond et al. [2014] was to determine if genetic variability within $I L-1 B$ and if specific IL- $1 \beta$ profiles contribute to post-traumatic epilepsy. Indeed, in a group of 59 adults with traumatic brain injury and available acute cytokine information, higher CSF/serum Il- $1 \beta$ ratios were associated with an increased risk for post-traumatic epilepsy. 
Interestingly, genetic analyses showed a significant relationship between a heterozygous CT genotype in a specific SNP (rs 1143634) and increased risk of post-traumatic epilepsy, shorter time to first seizure, lower serum IL-1 $\beta$ levels, higher CSF/serum ratio as well as increased $I L-1 \beta$ gene expression compared to CC or TT homozygous patients [Diamond et al., 2014]. The authors hypothesize that these findings reflect a genetic variability of the function of the blood-brain barrier after traumatic brain injury in certain individuals, which would allow proinflammatory cytokines to penetrate the CNS and cause permanent damage.

\section{Epilepsy in Tuberous Sclerosis Complex}

Tuberous sclerosis complex (TSC) is a rare neurocutaneous disease associated with mutations in TSC1 and TSC2, 2 tumor suppressor genes whose products (hamartin and tuberin, respectively) are involved in downregulation of the mammalian target of rapamycin complex 1 (mTORC1) [Saxena and Sampson, 2015]. Clinical symptoms are due to loss of function of these proteins leading to overactivation of mTORC1 signaling [Aronica and Crino, 2014]. This pathway modulates different cell development stages ranging from neuronal maturation to death and shares histopathological similarities to other focal malformations of cortical development [Lim and Crino, 2013].

Clinically, TSC is characterized by the development of hamartomatous lesions in various body organs, such as tubers in the CNS. The spectrum of clinical manifestations is large. Seizures occur in $75-90 \%$ of all patients [Thiele, 2004] and may present as epileptic spasms during the first year of life or as focal seizures related to cortical tubers. Refractory epilepsy may develop, and certain patients require surgical management to control seizures.

The pathophysiological mechanisms that underlie seizures in these patients are currently unknown. Inflammatory markers have been noted in cortical tubers or perituberal tissue [Boer et al., 2008a] and have long been suspected to play a role in seizure genesis in that disorder. Various research teams have studied the expression of certain genes in cortical tubers resected from patients who underwent epilepsy surgery. In addition to abnormal expression of genes encoding $\mathrm{GABA}_{\mathrm{A}}$ receptor subunits and glutamate receptors [White et al., 2001; Boer et al., 2008b; Talos et al., 2008], also observed in other forms of drug-resistant epilepsy, the expression of genes associated with the immune system and the inflammatory response, such as those encoding cell adhesion molecules, complement factors, serpin A3, chemokine ligand 2 and several cytokines, was also shown to be increased in tubers, compared to control tissues [Boer et al., 2010]. This phenomenon was particularly noted in tubers where the mTOR cascade is highly activated, suggesting a direct effect of the latter on that specific gene activation [Boer et al., 2010]. In addition, several proinflammatory cytokines such as TNF- $\alpha$ and IL- $1 \beta$ might intervene on the expression and disintegration of neurotransmitter receptors, thus, producing a stimulation or response blockage.

\section{Conclusion}

Certain channelopathies and dysfunctional neurotransmitter receptors are illustrative examples of wellstudied conditions causing neurological manifestations such as seizures via different mechanisms. These mechanisms include gene defects as well as immune system alterations. Important differences exist in the way these symptoms are expressed in both situations, even in the case of a same channel/receptor involvement. Why this is the case remains to be fully understood. Likewise, whether certain individuals carry a genetic predisposition to abnormal immune reactions related to seizures is currently unknown. Further studies in the field are of utmost importance to improve our current state of knowledge, which may open up interesting therapeutic approaches for patients with channelopathy-related seizures and epilepsy.

\section{Disclosure Statement}

The authors declare no conflicts of interest. 
Aronica E, Crino PB: Epilepsy related to develop- Carvill GL, Regan BM, Yendle SC, O’Roak BJ, Lomental tumors and malformations of cortical development. Neurotherapeutics 11:251-268 (2014).

Baysal-Kirac L, Tuzun E, Altindag E, Ekizoglu E, Kinay D, et al: Are there any specific EEG findings in autoimmune epilepsies? Clinical EEG Neurosci, E-pub ahead of print (2015).

Baysal-Kirac L, Tuzun E, Erdag E, Ulusoy C, Vanli-Yavuz EN, et al: Neuronal autoantibodies in epilepsy patients with peri-ictal autonomic findings. J Neurol 263:455-466 (2016).

- Berg AT, Berkovic SF, Brodie MJ, Buchhalter J, Cross JH, et al: Revised terminology and concepts for organization of seizures and epilepsies: report of the ILAE Commission on Classification and Terminology, 2005-2009. Epilepsia 51:676-685 (2010).

Bien CG, Bauer J: Autoimmune epilepsies. Neurotherapeutics 11:311-318 (2014).

Bisulli F, Tinuper P, Avoni P, Striano P, Striano S, et al: Idiopathic partial epilepsy with auditory features (IPEAF): a clinical and genetic study of 53 sporadic cases. Brain 127:1343-1352 (2004).

- Boer K, Jansen F, Nellist M, Redeker S, van den Ouweland AM, et al: Inflammatory processes in cortical tubers and subependymal giant cell tumors of tuberous sclerosis complex. Epilepsy Res 78:7-21 (2008a).

- Boer K, Troost D, Timmermans W, Gorter JA, Spliet WG, et al: Cellular localization of metabotropic glutamate receptors in cortical tubers and subependymal giant cell tumors of tuberous sclerosis complex. Neuroscience 156:203-215 (2008b).

Boer K, Crino PB, Gorter JA, Nellist M, Jansen FE, et al: Gene expression analysis of tuberous sclerosis complex cortical tubers reveals increased expression of adhesion and inflammatory factors. Brain Pathol 20:704-719 (2010).

Boillot M, Huneau C, Marsan E, Lehongre K, Navarro $\mathrm{V}$, et al: Glutamatergic neuron-targeted loss of LGI1 epilepsy gene results in seizures. Brain 137:2984-2996 (2014).

Boillot M, Lee CY, Allene C, Leguern E, Baulac S, Rouach N: LGI1 acts presynaptically to regulate excitatory synaptic transmission during early postnatal development. Sci Rep 6:21769 (2016).

Boronat A, Gelfand JM, Gresa-Arribas N, Jeong HY, Walsh M, et al: Encephalitis and antibodies to dipeptidyl-peptidase-like protein-6, a subunit of kv4.2 potassium channels. Ann Neurol 73:120-128 (2013).

-Brodtkorb E, Gu W, Nakken KO, Fischer C, Steinlein OK: Familial temporal lobe epilepsy with aphasic seizures and linkage to chromosome 10q22-q24. Epilepsia 43:228-235 (2002).

Carvajal-González A, Leite MI, Waters P, Woodhall M, Coutinho E, et al: Glycine receptor antibodies in PERM and related syndromes: characteristics, clinical features and outcomes. Brain 137:2178-2192 (2014). zovaya N, et al: GRIN2A mutations cause epilepsy-aphasia spectrum disorders. Nat Genet 45:1073-1076 (2013).

Chanson JB, Diaconu M, Honnorat J, Martin T, De Seze J, et al: PET follow-up in a case of anti-NMDR encephalitis: arguments for cingulate limbic encephalitis. Epileptic Disord 14:90-93 (2012).

Che F, Zhang Y, Wang G, Heng X, Liu S, Du Y: The role of GRIN2B in Tourette syndrome: results from a transmission disequilibrium study. J Affect Disord 187:62-65 (2015).

Conroy J, McGettigan PA, McCreary D, Shah N, Collins K, et al: Towards the identification of a genetic basis for Landau-Kleffner syndrome. Epilepsia 55:858-865 (2014).

Crisp SJ, Kullmann DM, Vincent A: Autoimmune synaptopathies. Nat Rev Neurosci 17: 103-117 (2016).

Dalmau J, Tuzun E, Wu HY, Masjuan J, Rossi JE, et al: Paraneoplastic anti-N-methyl-D-aspartate receptor encephalitis associated with ovarian teratoma. Ann Neurol 61:25-36 (2007).

Dalmau J, Gleichman AJ, Hughes EG, Rossi JE, Peng X, et al: Anti-NMDA-receptor encephalitis: case series and analysis of the effects of antibodies. Lancet Neurol 7:1091-1098 (2008).

Dalmau J, Lancaster E, Martinez-Hernandez E, Rosenfeld MR, Balice-Gordon R: Clinical experience and laboratory investigations in patients with anti-NMDR encephalitis. Lancet Neurol 10:63-74 (2011).

Dazzo E, Santulli L, Posar A, Fattouch J, Conti S, et al: Autosomal dominant lateral temporal epilepsy (ADLTE): novel structural and single-nucleotide $l$ GI1 mutations in families with predominant visual auras. Epilepsy Res 110: 132-138 (2015).

Diamond ML, Ritter AC, Failla MD, Boles JA, Conley YP, et al: IL- $1 \beta$ associations with posttraumatic epilepsy development: a genetics and biomarker cohort study. Epilepsia 55: 1109-1119 (2014).

Ekizoglu E, Tuzun E, Woodhall M, Lang B, Jacobson L, et al: Investigation of neuronal autoantibodies in two different focal epilepsy syndromes. Epilepsia 55:414-422 (2014).

Emsley HC, Appleton RE, Whitmore CL, Jury F, Lamb JA, et al: Variations in inflammationrelated genes may be associated with childhood febrile seizure susceptibility. Seizure 23: 457-461 (2014).

Endele S, Rosenberger G, Geider K, Popp B, Tamer C, et al: Mutations in GRIN2A and GRIN2B encoding regulatory subunits of NMDA receptors cause variable neurodevelopmental phenotypes. Nat Genet 42:1021-1026 (2010).

Epi4K Consortium; Epilepsy Phenome/Genome Project, Allen AS, Berkovic SF, Cossette P, et al: De novo mutations in epileptic encephalopathies. Nature 501:217-221 (2013).
Ferrari D, Villalba M, Chiozzi P, Falzoni S, Ricciardi-Castagnoli P, Di Virgilio F: Mouse microglial cells express a plasma membrane pore gated by extracellular ATP. J Immunol 156: 1531-1539 (1996).

Finke C, Kopp UA, Scheel M, Pech LM, Soemmer $\mathrm{C}$, et al: Functional and structural brain changes in anti-N-methyl-D-aspartate receptor encephalitis. Ann Neurol 74:284-296 (2013).

Flex E, Pizzuti A, Di Bonaventura C, Douzgou S, Egeo G, et al: LGI1 gene mutation screening in sporadic partial epilepsy with auditory features. J Neurol 252:62-66 (2005).

Florance NR, Davis RL, Lam C, Szperka C, Zhou L, et al: Anti-N-methyl-D-aspartate receptor (NMDAR) encephalitis in children and adolescents. Ann Neurol 66:11-18 (2009).

Frank LM, Shinnar S, Hesdorffer DC, Shinnar RC, Pellock JM, et al: Cerebrospinal fluid findings in children with fever-associated status epilepticus: results of the consequences of prolonged febrile seizures (FEBSTAT) study. J Pediatr 161:1169-1171 (2012).

Fukata Y, Lovero KL, Iwanaga T, Watanabe A, Yokoi N, et al: Disruption of lGI1-linked synaptic complex causes abnormal synaptic transmission and epilepsy. Proc Natl Acad Sci USA 107:3799-3804 (2010).

Gable MS, Sheriff H, Dalmau J, Tilley DH, Glaser CA: The frequency of autoimmune $\mathrm{N}$-methyl-D-aspartate receptor encephalitis surpasses that of individual viral etiologies in young individuals enrolled in the California Encephalitis Project. Clin Infect Dis 54:899-904 (2012).

Gatti S, Vezzani A, Bartfai T: Mechanisms of fever and febrile seizures: putative role of the interleukin-1 system, in Baram T, Shinnar S (eds): Febrile Seizures, pp 169-188 (Academic Press, San Diego 2002).

- Granger AJ, Shi Y, Lu W, Cerpas M, Nicoll RA: LTP requires a reserve pool of glutamate receptors independent of subunit type. Nature 493:495-500 (2013).

-Graves TD, Cha YH, Hahn AF, Barohn R, Salajegheh MK, et al: Episodic ataxia type 1: clinical characterization, quality of life and genotype-phenotype correlation. Brain 137:10091018 (2014).

Greenberg D, Holmes G: The genetics of febrile seizures, in Baram T, Shinnar S (eds): Febrile Seizures, pp 249-264 (Academic Press, San Diego 2002).

Gu W, Brodtkorb E, Steinlein OK: LGI1 is mutated in familial temporal lobe epilepsy characterized by aphasic seizures. Ann Neurol 52: 364-367 (2002).

Hacohen Y, Absoud M, Hemingway C, Jacobson $L$, Lin JP, et al: NMDA receptor antibodies associated with distinct white matter syndromes. Neurol Neuroimmunol Neuroinflamm 1:e2 (2014).

-Ho YY, Ionita-Laza I, Ottman R: Domain-dependent clustering and genotype-phenotype analysis of LGI1 mutations in ADPEAF. Neurology 78:563-568 (2012).
Seizures and Channelopathies, Genetic and Immune Aspects
Mol Syndromol 2016;7:197-209 DOI: $10.1159 / 000447707$ 
-Höftberger R, van Sonderen A, Leypoldt F, Kruer MC, Hoeftberger R, Lim KY, Coryell JC, Houghton D, Geschwind M, et al: Encephalitis and AMPA receptor antibodies: novel findings in a case series of 22 patients. Neurology 84:2403-2412 (2015).

-Hong SE, Shugart YY, Huang DT, Shahwan SA, Grant PE, et al: Autosomal recessive lissencephaly with cerebellar hypoplasia is associated with human RELN mutations. Nat Genet 26:93-96 (2000)

-Hughes EG, Peng X, Gleichman AJ, Lai M, Zhou $\mathrm{L}$, et al: Cellular and synaptic mechanisms of anti-NMDA receptor encephalitis. J Neurosci 30:5866-5875 (2010).

-Irani SR, Alexander S, Waters P, Kleopa KA, Pettingill $\mathrm{P}$, et al: Antibodies to Kv1 potassium channel-complex proteins leucine-rich, glioma inactivated 1 protein and contactin-associated protein-2 in limbic encephalitis, Morvan's syndrome and acquired neuromyotonia. Brain 133:2734-2748 (2010).

Irani SR, Michell AW, Lang B, Pettingill P, Waters P, et al: Faciobrachial dystonic seizures precede lgil antibody limbic encephalitis. Ann Neurol 69:892-900 (2011)

-Irani SR, Stagg CJ, Schott JM, Rosenthal CR, Schneider SA, et al: Faciobrachial dystonic seizures: the influence of immunotherapy on seizure control and prevention of cognitive impairment in a broadening phenotype. Brain 136:3151-3162 (2013).

-Jagota P, Vincent A, Bhidayasiri R: Transplacental transfer of NMDA receptor antibodies in an infant with cortical dysplasia. Neurology 82:1662-1663 (2014).

- Joubert B, Kerschen P, Zekeridou A, Desestret V, Rogemond V, et al: Clinical spectrum of encephalitis associated with antibodies against the $\alpha$-amino-3-hydroxy-5-methyl-4-isoxazolepropionic acid receptor: case series and review of the literature. JAMA Neurol 72: 1163-1169 (2015).

Kauffman MA, Moron DG, Consalvo D, Bello R, Kochen S: Association study between interleukin $1 \beta$ gene and epileptic disorders: a $\mathrm{HuGe}$ review and meta-analysis. Genet Med 10:83-88 (2008).

- Kesim YF, Uzun GA, Yucesan E, Tuncer FN, Ozdemir O, et al: Screening LGI1 in a cohort of 26 lateral temporal lobe epilepsy patients with auditory aura from Turkey detects a novel de novo mutation. Epilepsy Res 120:73-78 (2015).

-Klein CJ, Lennon VA, Aston PA, McKeon A, O'Toole $\mathrm{O}$, et al: Insights from LGI1 and CASPR2 potassium channel complex autoantibody subtyping. JAMA Neurol 70:229-234 (2013).

-Klein KM, Pendziwiat M, Cohen R, Appenzeller $S$, de Kovel CG, et al: Autosomal dominant epilepsy with auditory features: a new LGI1 family including a phenocopy with cortical dysplasia. J Neurol 263:11-16 (2016).

-Kobayashi E, Santos NF, Torres FR, Secolin R, Sardinha LA, et al: Magnetic resonance imaging abnormalities in familial temporal lobe epilepsy with auditory auras. Arch Neurol 60: 1546-1551 (2003). Svoboda MD, et al: Aggressive course in encephalitis with opsoclonus, ataxia, chorea, and seizures: the first pediatric case of $\gamma$ aminobutyric acid type $B$ receptor autoimmunity. JAMA Neurol 71:620-623 (2014).

Lai M, Huijbers MG, Lancaster E, Graus F, Bataller L, et al: Investigation of LGI1 as the antigen in limbic encephalitis previously attributed to potassium channels: a case series. Lancet Neurol 9:776-785 (2010).

Lal D, Steinbrücker S, Schubert J, Sander T, Becker F, et al: Investigation of GRIN2A in common epilepsy phenotypes. Epilepsy Res 115: 95-99 (2015)

Lalic T, Pettingill P, Vincent A, Capogna M: Human limbic encephalitis serum enhances hippocampal mossy fiber-CA3 pyramidal cell synaptic transmission. Epilepsia 52:121-131 (2011).

-Lancaster E, Martinez-Hernandez E, Titulaer MJ, Boulos M, Weaver S, et al: Antibodies to metabotropic glutamate receptor 5 in the Ophelia syndrome. Neurology 77:1698-1701 (2011).

Lee CH, Lin JJ, Lin KJ, Chang BL, Hsieh HY, et al: Caspr2 antibody limbic encephalitis is associated with Hashimoto thyroiditis and thymoma. J Neurol Sci 341:36-40 (2014).

Lee LC, Cho YC, Lin PJ, Yeh TC, Chang CY, Yeh TK: Influence of genetic variants of the Nmethyl-D-aspartate receptor on emotion and social behavior in adolescents. Neural Plast 2016:6851592 (2016).

Lemke JR, Lal D, Reinthaler EM, Steiner I, Nothnagel M, et al: Mutations in GRIN2A cause idiopathic focal epilepsy with rolandic spikes. Nat Genet 45:1067-1072 (2013).

-Lemke JR, Hendrickx R, Geider K, Laube B, Schwake M, et al: GRIN2B mutations in West syndrome and intellectual disability with focal epilepsy. Ann Neurol 75:147-154 (2014).

Lesca G, Rudolf G, Bruneau N, Lozovaya N, Labalme A, et al: GRIN2A mutations in acquired epileptic aphasia and related childhood focal epilepsies and encephalopathies with speech and language dysfunction. Nat Genet 45: 1061-1066 (2013)

Lim KC, Crino PB: Focal malformations of cortical development: new vistas for molecular pathogenesis. Neuroscience 252:262-276 (2013).

Lu KT, Wang YW, Yang JT, Yang YL, Chen HI: Effect of interleukin-1 on traumatic brain injury-induced damage to hippocampal neurons. J Neurotrauma 22:885-895 (2005).

-Maeder-Ingvar M, Prior JO, Irani SR, Rey V, Vincent A, Rossetti AO: FDG-PET hyperactivity in basal ganglia correlating with clinical course in anti-NDMA-R antibodies encephalitis. J Neurol Neurosurg Psychiatry 82:235236 (2011).
Mantegazza R, Bernasconi P, Baggi F, Spreafico R, Ragona F, et al: Antibodies against GLuR3 peptides are not specific for Rasmussen's encephalitis but are also present in epilepsy patients with severe, early onset disease and intractable seizures. J Neuroimmunol 131:179185 (2002).

- Matin N, Tabatabaie O, Falsaperla R, Lubrano R, Pavone $\mathrm{P}$, et al: Epilepsy and innate immune system: a possible immunogenic predisposition and related therapeutic implications. Hum Vaccin Immunother 11:2021-2029 (2015).

Michelucci R, Poza JJ, Sofia V, de Feo MR, Binelli S, et al: Autosomal dominant lateral temporal epilepsy: clinical spectrum, new epitempin mutations, and genetic heterogeneity in seven European families. Epilepsia 44:12891297 (2003).

-Michelucci R, Pasini E, Malacrida S, Striano P, Bonaventura CD, et al: Low penetrance of autosomal dominant lateral temporal epilepsy in Italian families without LGI1 mutations. Epilepsia 54:1288-1297 (2013).

Moscato EH, Peng X, Jain A, Parsons TD, Dalmau J, Balice-Gordon RJ: Acute mechanisms underlying antibody effects in anti-N-methylD-aspartate receptor encephalitis. Ann Neurol 76:108-119 (2014)

Naasan G, Irani SR, Bettcher BM, Geschwind MD, Gelfand JM: Episodic bradycardia as neurocardiac prodrome to voltage-gated potassium channel complex/leucine-rich, glioma inactivated 1 antibody encephalitis. JAMA Neurol 71:1300-1304 (2014).

- Nobile C, Michelucci R, Andreazza S, Pasini E, Tosatto SC, Striano P: LGI1 mutations in autosomal dominant and sporadic lateral temporal epilepsy. Hum Mutat 30:530-536 (2009).

Nordli DR Jr, Moshé SL, Shinnar S, Hesdorffer DC, Sogawa Y, et al: Acute EEG findings in children with febrile status epilepticus: results of the FEBSTAT study. Neurology 79:21802186 (2012).

- Ohkawa T, Fukata Y, Yamasaki M, Miyazaki T, Yokoi N, et al: Autoantibodies to epilepsy-related LGI1 in limbic encephalitis neutralize LGI1-ADAM22 interaction and reduce synaptic AMPA receptors. J Neurosci 33:1816118174 (2013).

Ong MS, Kohane IS, Cai T, Gorman MP, Mandl KD: Population-level evidence for an autoimmune etiology of epilepsy. JAMA Neurol 71: 569-574 (2014).

Ottman R, Winawer MR, Kalachikov S, BarkerCummings C, Gilliam TC, et al: LGI1 mutations in autosomal dominant partial epilepsy with auditory features. Neurology 62:11201126 (2004).

-Ottman R: Autosomal dominant partial epilepsy with auditory features, in Pagon RA, Adam MP, Ardinger HH, Wallace SE, Amemiya A, et al (eds): GeneReviews ${ }^{\circledR}$ [Internet] (University of Washington, Seattle 2007). 
Pan Y, Chen J, Guo H, Ou J, Peng Y, et al: Association of genetic variants of GRIN2B with autism. Sci Rep 5:8296 (2015).

-Peng X, Hughes EG, Moscato EH, Parsons TD, Dalmau J, Balice-Gordon RJ: Cellular plasticity induced by anti-alpha-amino-3-hydroxy5-methyl-4-isoxazolepropionic acid (AMPA) receptor encephalitis antibodies. Ann Neurol 77:381-398 (2015).

- Pernhorst K, Herms S, Hoffmann P, Cichon S, Schulz H, et al: TLR4, ATF-3 and IL8 inflammation mediator expression correlates with seizure frequency in human epileptic brain tissue. Seizure 22:675-678 (2013).

Petit-Pedrol M, Armangue T, Peng X, Bataller L, Cellucci T, et al: Encephalitis with refractory seizures, status epilepticus, and antibodies to the $\mathrm{GABA}_{\mathrm{A}}$ receptor: a case series, characterisation of the antigen, and analysis of the effects of antibodies. Lancet Neurol 13:276-286 (2014).

- Picascia A, Grimaldi V, Pignalosa O, De Pascale MR, Schiano C, Napoli C: Epigenetic control of autoimmune diseases: from bench to bedside. Clin Immunol 157:1-15 (2015).

-Pisano T, Marini C, Brovedani P, Brizzolara D, Pruna D, et al: Abnormal phonologic processing in familial lateral temporal lobe epilepsy due to a new LGI1 mutation. Epilepsia 46: 118-123 (2005).

-Pollak TA, Nicholson TR, Mellers JD, Vincent A, David AS: Epilepsy-related psychosis: a role for autoimmunity? Epilepsy Behav 36:33-38 (2014).

Robbins CA, Tempel BL: Kv1.1 and Kv1.2: similar channels, different seizure models. Epilepsia 53 Suppl 1:134-141 (2012).

Rocamora R, Becerra JL, Fossas P, Gomez M, Vivanco-Hidalgo RM, et al: Pilomotor seizures: an autonomic semiology of limbic encephalitis? Seizure 23:670-673 (2014).

Rogers SW, Andrews PI, Gahring LC, Whisenand $\mathrm{T}$, Cauley K, et al: Autoantibodies to glutamate receptor GluR3 in Rasmussen's encephalitis. Science 265:648-651 (1994).

Rosanoff MJ, Ottman R: Penetrance of LGI1 mutations in autosomal dominant partial epilepsy with auditory features. Neurology 71:567571 (2008).

-Sands TT, Nash K, Tong S, Sullivan J: Focal seizures in children with anti-NMDA receptor antibody encephalitis. Epilepsy Res 112:3136 (2015).

-Saxena A, Sampson JR: Epilepsy in tuberous sclerosis: phenotypes, mechanisms, and treatments. Semin Neurol 35:269-276 (2015).
-Schmitt SE, Pargeon K, Frechette ES, Hirsch LJ, Dalmau J, Friedman D: Extreme delta brush: a unique EEG pattern in adults with antiNMDA receptor encephalitis. Neurology 79: 1094-1100 (2012).

Schulte U, Thumfart JO, Klöcker N, Sailer CA, Bildl W, et al: The epilepsy-linked LGI1 protein assembles into presynaptic Kv1 channels and inhibits inactivation by $\operatorname{Kv} \beta 1$. Neuron 49 : 697-706 (2006).

Shahrokhi A, Zare-Shahabadi A, Soltani S, Ashrafi MR, Zoghi S, et al: Association of IL6 single nucleotide polymorphisms with febrile seizures. J Neurol Sci 342:25-28 (2014).

Shinnar S, Bello JA, Chan S, Hesdorffer DC, Lewis DV, et al: MRI abnormalities following febrile status epilepticus in children: The FEBSTAT study. Neurology 79:871-877 (2012).

- Singh NA, Westenskow P, Charlier C, Pappas C, Leslie J, et al: KCNQ2 and KCNQ3 potassium channel genes in benign familial neonatal convulsions: expansion of the functional and mutation spectrum. Brain 126:2726-2737 (2003).

Stafstrom C: The incidence and prevalence of febrile seizures, in Baram T, Shinnar S (eds): Febrile Seizures, pp 1-25 (Academic Press, San Diego 2002).

-Sunwoo JS, Lee ST, Byun JI, Moon J, Shin JW, et al: Clinical manifestations of patients with CASPR2 antibodies. J Neuroimmunol 281: 17-22 (2015).

Szots M, Marton A, Kover F, Kiss T, Berki T, et al: Natural course of LGI1 encephalitis: $3-5$ years of follow-up without immunotherapy. J Neurol Sci 343:198-202 (2014).

-Talos DM, Kwiatkowski DJ, Cordero K, Black PM, Jensen FE: Cell-specific alterations of glutamate receptor expression in tuberous sclerosis complex cortical tubers. Ann Neurol 63:454-465 (2008).

Tan KM, Lennon VA, Klein CJ, Boeve BF, Pittock SJ: Clinical spectrum of voltage-gated potassium channel autoimmunity. Neurology 70: 1883-1890 (2008).

-Tessa C, Michelucci R, Nobile C, Giannelli M, Della Nave R, et al: Structural anomaly of left lateral temporal lobe in epilepsy due to mutated LGI1. Neurology 69:1298-1300 (2007).

Thiele EA: Managing epilepsy in tuberous sclerosis complex. J Child Neurol 19:680-686 (2004).
Titulaer MJ, McCracken L, Gabilondo I, Armangué T, Glaser C, et al: Treatment and prognostic factors for long-term outcome in patients with anti-NMDA receptor encephalitis: an observational cohort study. Lancet Neurol 12: 157-165 (2013).

Turner SJ, Morgan AT, Perez ER, Scheffer IE: Erratum to: New genes for focal epilepsies with speech and language disorders. Curr Neurol Neurosci Rep 15:55 (2015a).

Turner SJ, Morgan AT, Perez ER, Scheffer IE: New genes for focal epilepsies with speech and language disorders. Curr Neurol Neurosci Rep 15:35 (2015b).

-Vincent A: Autoimmune channelopathies: wellestablished and emerging immunotherapyresponsive diseases of the peripheral and central nervous systems. J Clin Immunol 30(Suppl 1):S97-102 (2010).

-Vincent A, Irani SR: CASPR2 antibodies in patients with thymomas. J Thorac Oncol 5: S277-280 (2010).

-Vincent A, Buckley C, Schott JM, Baker I, Dewar $\mathrm{BK}$, et al: Potassium channel antibody-associated encephalopathy: a potentially immunotherapy-responsive form of limbic encephalitis. Brain 127:701-712 (2004).

-Wagner J, Weber B, Elger CE: Early and chronic gray matter volume changes in limbic encephalitis revealed by voxel-based morphometry. Epilepsia 56:754-761 (2015).

-Weckhuysen S, Mandelstam S, Suls A, Audenaert $\mathrm{D}$, Deconinck T, et al: KCNQ2 encephalopathy: emerging phenotype of a neonatal epileptic encephalopathy. Ann Neurol 71:15-25 (2012).

White R, Hua Y, Scheithauer B, Lynch DR, Henske EP, Crino PB: Selective alterations in glutamate and GABA receptor subunit mRNA expression in dysplastic neurons and giant cells of cortical tubers. Ann Neurol 49:67-78 (2001).

Wong SH, Saunders MD, Larner AJ, Das K, Hart IK: An effective immunotherapy regimen for VGKC antibody-positive limbic encephalitis. J Neurol Neurosurg Psychiatry 81:1167-1169 (2010).

-Yu YE, Wen L, Silva J, Li Z, Head K, et al: Lgil null mutant mice exhibit myoclonic seizures and CA1 neuronal hyperexcitability. Hum Mol Genet 19:1702-1711 (2010).

Zhou YD, Lee S, Jin Z, Wright M, Smith SE, Anderson MP: Arrested maturation of excitatory synapses in autosomal dominant lateral temporal lobe epilepsy. Nat Med 15:1208-1214 (2009).
Seizures and Channelopathies, Genetic and Immune Aspects
Mol Syndromol 2016;7:197-209 DOI: $10.1159 / 000447707$ 